\title{
97. Application of wheeled platforms for special purpose vehicle
}

\author{
Grzegorz Szczęśniak ${ }^{1}$, Paulina Nogowczyk ${ }^{2}$, Rafał Burdzik ${ }^{3}$, Lukasz Konieczny ${ }^{4}$ \\ ${ }^{1,2}$ SZCZEŚŚNIAK Pojazdy Specjalne Sp. z. o. o., Bestwińska Street 105A, 43-346 Bielsko-Biała, Poland \\ ${ }^{3,4}$ Faculty of Transport Silesian University of Technology, Krasińskiego Street 8, 40-019 Katowice, Poland \\ ${ }^{3}$ Corresponding author \\ E-mail: ${ }^{1}$ gszczesniak@psszczesniak.pl, ${ }^{2}$ pnogowczyk@psszczesniak.pl, ${ }^{3}$ rafal.burdzik@polsl.pl, \\ ${ }^{4}$ lukasz.konieczny@polsl.pl
}

Received 21 April 2016; accepted 16 June 2016

DOI http://dx.doi.org/10.21595/jme.2016.17296

\begin{abstract}
The paper presents High Mobility Wheeled Platform as example of new generation of military vehicles. It describes different types of special purpose vehicles with innovation direction of development. The concept of the article based on comparison of requirements and properties of wheeled platforms and special purpose vehicles. Thus the evolution of wheeled platform has been also presented. As the result of analysis and example of application the High Mobility Wheeled Platform was described.
\end{abstract}

Keywords: special purpose vehicle (SPV), wheeled platform.

\section{Introduction}

The market of special vehicles is one of the fastest growth automotive areas. Many customers require untypical properties of the cars or trucks. Also the purposes of functionality are to evolve and become much more specialized. Thus we can select military vehicles, special service vehicles (i.e. ambulance, fire truck, police), rescue cars, airport vehicles and many more $[1,2]$.

The paper presents new generation of special vehicles and applications of wheeled platforms for special purpose vehicle. The scope of the analysis was limited into wheeled platform designed to transport loads. These type of vehicles have large scope of loads, from general cargo to concrete. It can be designed, developed, produced and installed truck bodies and trailers for any kind of use according to special and individual requirements.

Requirements for special vehicles are determined objective function and very often significantly different from the mass-produced vehicles. Often they are in conflict with the requirements, standards, or even type approval regulations [3, 4].

\section{Analysis of special purpose vehicles}

Due to the functionality requirements and operation parameters the vehicles can be grouped according to purpose of operation. The largest number of special purpose vehicle (SPV) are based on trucks construction $[4,5]$. Thus it has been presented chosen examples of special purpose trucks as advanced modification of mass-produced trucks or self-designed heavy vehicles or swap body vehicles.

Probably the most representative SPV are military vehicles. The purposes of military vehicles are much different than mass-produced trucks. They have to be resisted for the different atmospherics conditions, wear and corrosion processes. Also military vehicles have to drive and operate in terrain and they have to support the mission standards. Military trucks are designed for use by military forces to transport cargo - including fuel, ammunition and other vehicles. As the examples of military trucks the assists of Finland's defence force Saurus and Sisu have been presented in Fig. 1. The Sisu $8 \times 8$ is high mobility tactical vehicle based on the E11T $6 \times 6$ platform. This military truck was specially designed for operation in northern conditions. It combines excellent on road and off-road mobility with large payload capacity under extreme climatic and terrain conditions. One of the most mobile and reliable military truck is MAN SX (German, Fig. 2). This is heavy high mobility truck designed to operate in tough off-road conditions and is 
also used as a load handling system to carry flatracks and containers. It has a modular cab, which can be fitted with add-on armor protection kit $[6,7]$.

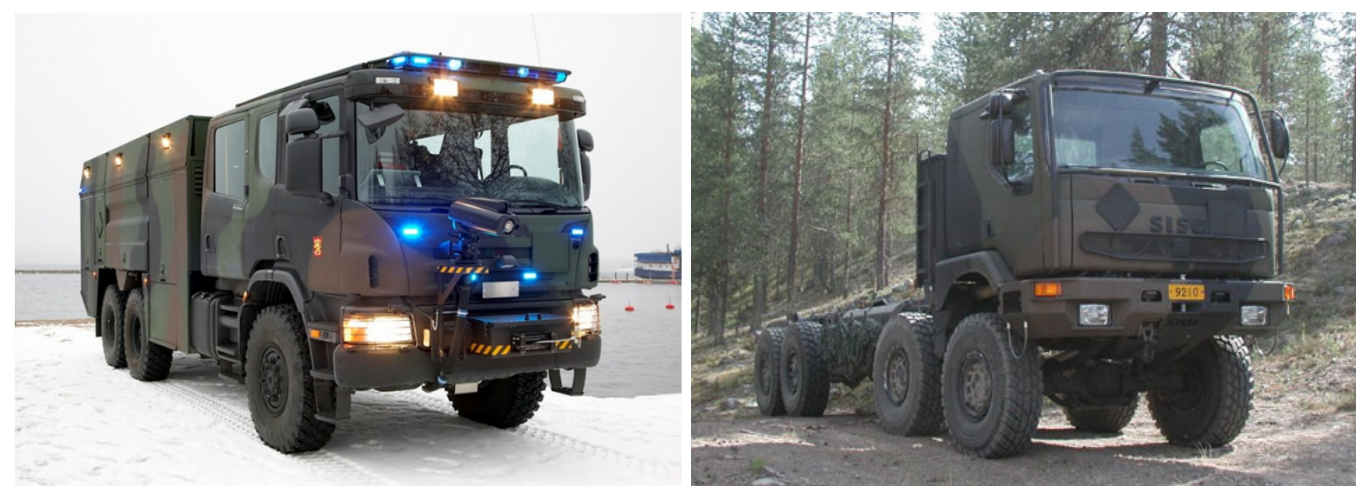

Fig. 1. Military trucks - Finland's defence force (Saurus, SISU) [6, 7]

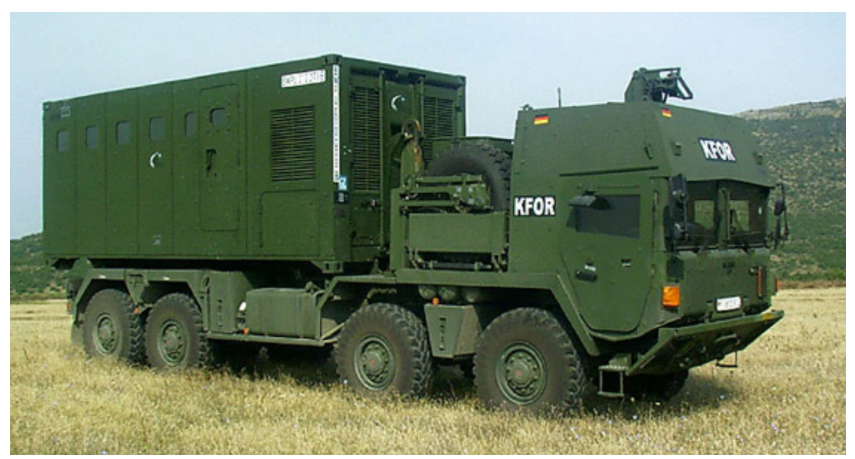

Fig. 2. Military truck - MAN SX45 [6]

Other group of SPV are self-designed innovative vehicles. It is concept, design and produce strict with the special purposes. Thus its operational properties are often limited to the designed purposes but also performed high efficiency of functionality [8]. As the example the new Panther made by Rosenbauer. The Fig. 3 presents 4th generation of the Panther - ARFF vehicle (airport fire fighter). The innovations have been noted on the Fig. 3.

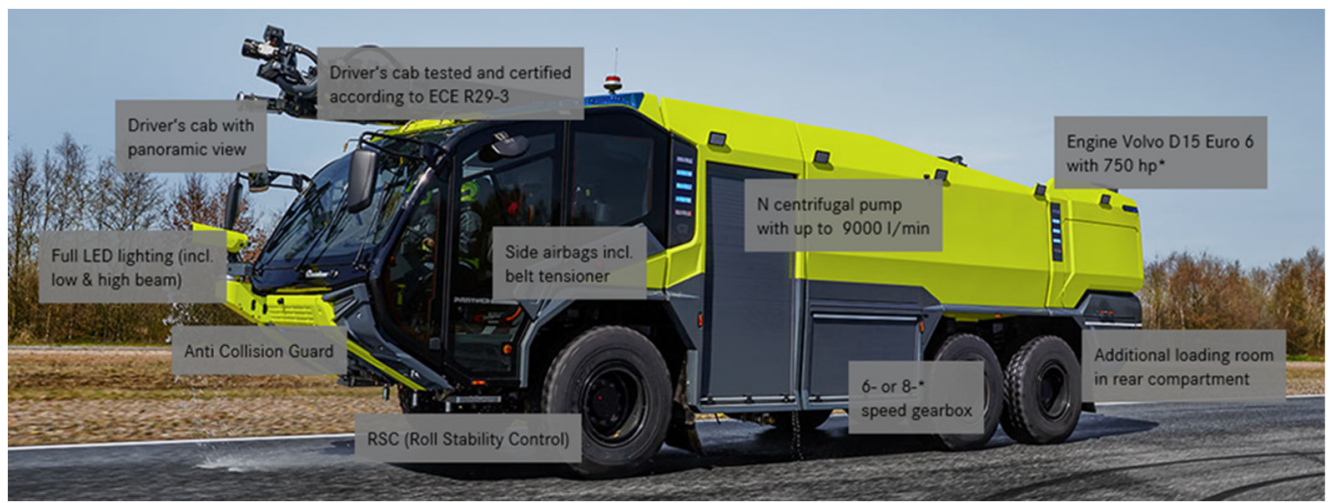

Fig. 3. Self-designed innovative SPV [8]

SPV are designed or modified for the defined activities. It generates highest production costs probably for small target of customers. Thus at the beginning the main trend was to modified 
mass-produced vehicles based on chassis and suspension. The group of self-designed SPV is limited by production cost. Thus new trend of SPV development is observed. The fundamental special vehicle with changeable body for the special purpose. Certain operational actions require various sorts of vehicle equipment. The Fig. 4 presents roll-off containers on swap body trucks. It is very efficient solution for the highest flexibility for the transportation of equipment that is only needed in certain situations.

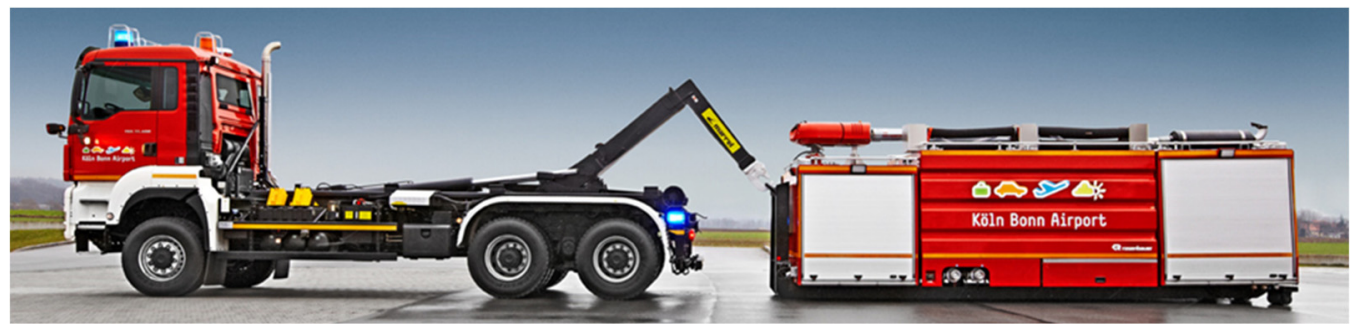

Fig. 4. Swap body vehicles - Roll-off containers [8]

\section{Evolution of wheeled platform}

The purpose of the paper is to present the new generation of mobile wheeled platform. Wheeled platform is perfect example of mean of transport for cargo transportation with low limitation of the sort of load. Thus it is required high capacity, simple construction and large size of platform with regular shape. It will guarantee the susceptibility of mobility and load. The properties of wheeled platform are perfectly fulfilled with industrial transport. Thus as the simple example of first solution of wheeled platform the industrial truck can be considered. Industrial trucks are used to move materials over variable paths, with no restrictions on the area covered by the movement. The large rectangular platform supported by 3 or 4 wheels, without suspension system and power engine, is example of very universal vehicle (dolly) for cargo transportation. The industrial truck, wheeled platform, have been depicted in Fig. 5.

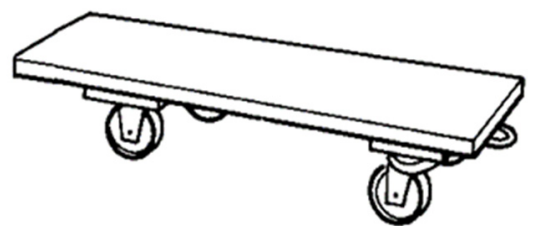

Fig. 5. Wheeled platform - industrial dolly [9]

The universal properties of wheeled platform determine evolution of technical solutions and high applicability in many fields. As the example of unlimited extended of the wheeled platform the robot platform can be presented. It is industry or many other purposes leader in mobile platform technologies. Nowadays it offers a variety of platform configurations that come standard with features to make them the most versatile, easy to configure and operate transport systems. The most important properties of robot wheel platform are open architecture, four-wheel steering, heavy payload capabilities and high speeds. As far as it is distance control system without operator inside the platform it makes large number fields of applications: military, industrial and research operations. Robot wheeled platforms are commonly used for space missions to explore new environment in unexpected terrain condition. Some examples of application of robot wheeled platforms have been depicted in Fig. 6. The basic variant is industry leader with payload up to $250 \mathrm{~kg}$, which is very good for such size of mean of transport (Fig. 6(a)). As the example of application the Explosive Ordnance Disposal has been presented in Fig. 6(b). This solution leverage the fast top speed to get the robot to suspected explosive destination quickly, while taking advantage of its precise low speed control to inspect and dispose of threats. 
As far as wheeled platform was created and still developed for the purpose of cargo transportation some attempts were made to use it for the human transportation vehicle (HTV). The latest innovations introduced large group of self-balancing wheel scooter based on solution of two-wheeled platform (Fig. 7). The platform is controlled by the operator standing on the built-in gyroscopic, sensored pads. Thus the operator hands are free, which is perfect solution for the support of the city transport system. The user is able to carry bag, laptop or even talk by cell phone. Currently the main scope of research on this field is method of control and self-balancing of two-wheeled platform. For example, the paper [10] presents adaptive robust regulation methods for self-balancing and yaw motion of a two-wheeled platform with varying payload and system uncertainties. The paper [11] presents an adaptive control using radial-basis-function neural networks.

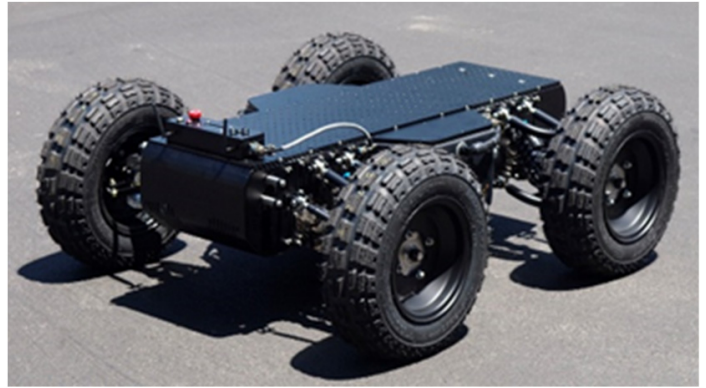

a)

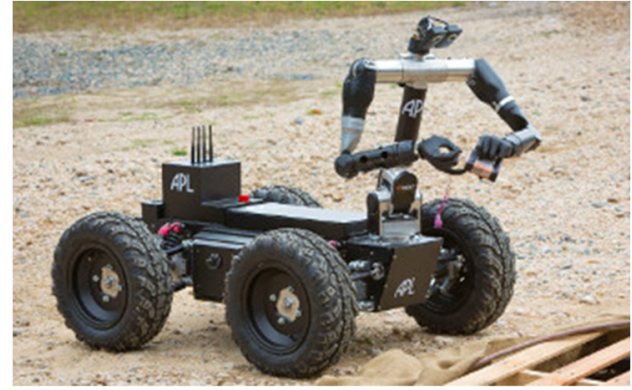

b)

Fig. 6. Robot wheeled platforms: a) industry leader (basic) and b) explosive ordnance disposal [12]

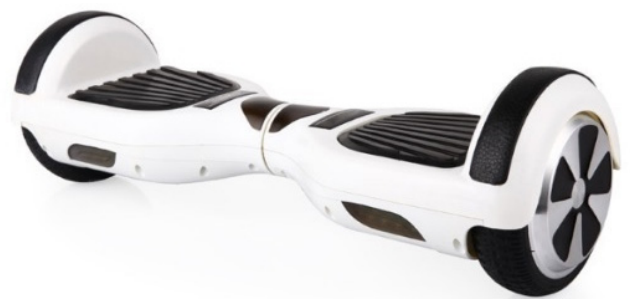

Fig. 7. Self-balancing two-wheel scooter (HTV) [13]

\section{High Mobility Wheeled Platform - new generation of military vehicles}

The requirements on special purpose vehicle as military vehicle and universal properties of wheeled platform were starting point for project and design on new high mobility military vehicle. The idea of military wheeled platform was developed since the end of the World War II, when the needs of support operations were exposed. British army used various air-transportable ultra-lightweight vehicles that provide transport and logistic support to airborne troops or infantry that operate in extreme conditions. The most recognized is All Terrain Mobility Platform Supacat. It is an example of lightweight 6-wheeled platform (Fig. 8).

Modern military vehicles must meet a number of different requirements in terms of technology, constructions, ergonomics and configuration options giving many possibilities of their use in the armed forces. High Mobility Wheeled Platform (KPWM) is an example of a new generation special vehicle. The concept of High Mobility Wheeled Platform is to provide excellent drivability characteristics, high capacity and modularity in rough terrain and enabling further vehicle's construction development. The modular construction of KPWM allows easy platform for performing modifications and modernization, extremely important in the life cycle of devices and military equipment. The vehicle is equipped with gearbox reducer and differentials, essential when driving off-road. Thus it is suitable to work in all conditions. The presentation of driving 
possibilities in all terrain condition of KPWM have been depicted in Fig. 9.

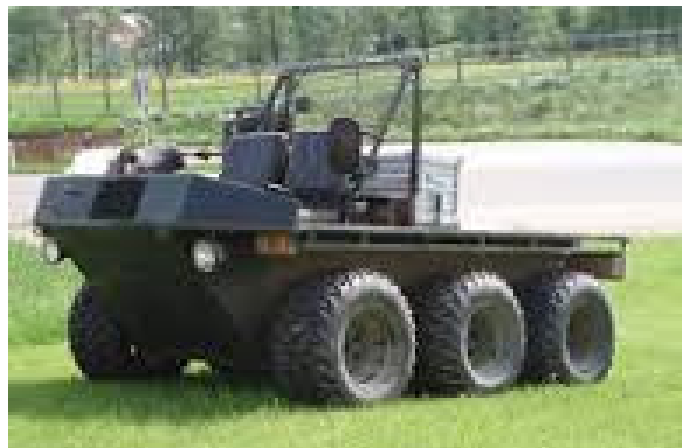

Fig. 8. All terrain mobility platform - Supacat [14]
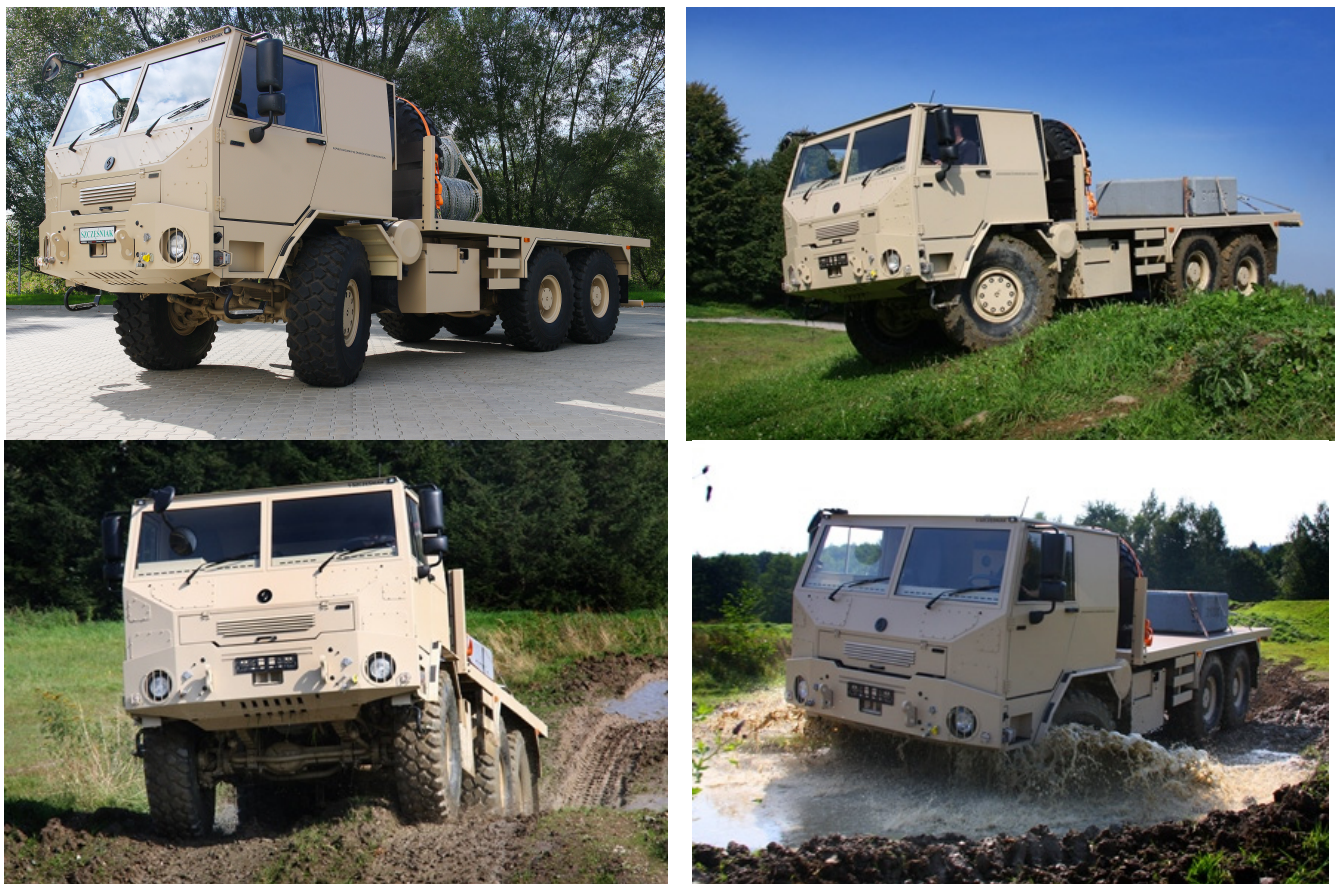

Fig. 9. Driving possibilities in all terrain condition of KPWM [15]

The forces and the reactions occurring between the sprung and unsprung masses of the vehicles can be destructive. Thus an important elements become connecting the wheels and axles of the vehicle, the frame and body. In trucks, mass ratios of these elements necessitate consideration of dynamic phenomena in another scope. In the case of special vehicles, where there is the need to adapt its body weight can significantly increase depending on the required equipment.

The main frame of KPWM is the backbone of the entire vehicle, which supports all elements. It should meet the strength requirements set up to carry the burden of rough roads, and the load from the body and its parts and cargo that will be transported. The suspension uses the elastic elements such as reinforced parabolic leaf springs (front), semi-elliptical leaf springs (rear), shocks and stabilizer, in order to reduce lateral body roll during cornering. The full assembly frame of High Mobility Wheeled Platform has been depicted in Fig. 10.

One of the purposes of military vehicle is full readiness to mission in all around the world. Thus the vehicle needs ability to be transported by any mean of transport. The compactness of the 
modular structure characterizing the KPWN vehicle, enables its transportation by various means of transport, for example: train, boat, airplane or helicopter.

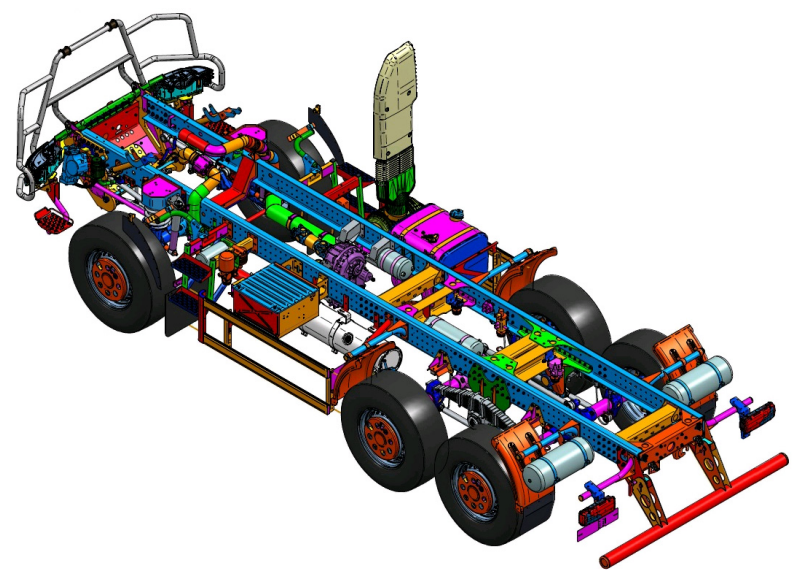

Fig. 10. The full assembly frame of high mobility wheeled platform [15]

\section{Conclusions}

A specific example of special-purpose vehicles are military vehicles. High Mobility Wheeled Platform is an example of a new generation of special-purpose vehicle dedicated to the military sector. Essential requirements of the objective function of this group of vehicles are good traction on paved roads and in irregular terrain, high capacity and modularity, as well as the ability to adapt and designed to allow further modifications.

This wheeled platform is a vehicle built in a $6 \times 6$ drive, featuring the advantages of a $4 \times 4$ vehicle. Due to the requirements of uptime operation in all conditions limited the use of advanced design of mechanical systems and mechatronics, which often limits the reliability of the work environment.

The paper shows some directions in evolution of special purpose vehicles with applications of well-known and simple solutions of wheeled platforms.

\section{Acknowledgements}

This article is the result of Research Programme DEMONSTRATOR + Supporting Scientific Research and Development Works in Demonstration Scale, the title of the Project is Develop High Mobility Wheeled Platform for Special Applications (No. WND-DEM-1-325/00 KoPlatWysMob).

\section{References}

[1] Szczęśniak G., Nogowczyk P., Burdzik R. Some basic tips in vehicle chassis and frame design. Journal of Measurements in Engineering, Vol. 2, Issue 4, 2014, p. 208-214.

[2] Ostrowski T., Nogowczyk P., Burdzik R. The constructional solutions for absorption of vibration in special vehicles operated in terrain. Vibroengineering Procedia, Vol. 3, 2014, p. 249-253.

[3] Ostrowski T., Nogowczyk P., Burdzik R., Konieczny L. Technical elements for minimising of vibration effects in special vehicles. Vibroengineering Procedia, Vol. 6, 2015, p. 259-263.

[4] Szczęśniak G., Nogowczyk P., Burdzik R., Konieczny Ł. Requirements for construction of the bodies of special vehicles. Scientific Journal of Silesian University of Technology, Series Transport Vol. 87, Issue 2015, 2015, p. 73-79.

[5] Szczęśniak G., Nogowczyk P., Burdzik R., Konieczny Ł. Application of mounting frames in special vehicles. Scientific Journal of Silesian University of Technology, Series Transport, Vol. 87, 2015, p. 81-86. 
[6] http://www.mfteam.hu

[7] http://www.military-today.com/trucks/sisu e11t 8x8.htm

[8] http://rosenbauer-panther.com/

[9] http://www.ise.ncsu.edu

[10] Lin Shui-Chun, Tsai Ching-Chih, Huang Hsu-Chih Adaptive robust self-balancing and steering of a two-wheeled human transportation vehicle. Journal of Intelligent and Robotic Systems, Vol. 62, Issue 1, 2011, p. 103-123.

[11] Tsai Ching-Chih, Huang Hsu-Chih, Lin Shui-Chun Adaptive neural network control of a self-balancing two-wheeled scooter. IEEE Transactions on Industrial Electronics, Vol. 57, Issue 4, 2010, p. 1420-1428.

[12] http:// www.ambot.com

[13] http:// www.whateverskateboards.com

[14] http:// www.flickr.com

[15] Materials provided by Szczesniak Pojazdy Specjalne.

[16] Nogowczyk P., Szczęśniak G., Konieczny L., Burdzik R. Non-conventional suspension systems in heavy special-purpose trucks. Vibroengineering Procedia, Vol. 6, 2015, p. 254-258. 